\title{
Dysbiosis in intestinal microbiome linked to fecal blood determined by direct hybridization
}

\author{
Concetta Cafiero ${ }^{1,2} \cdot$ Agnese $\mathrm{Re}^{2,3} \cdot$ Salvatore Pisconti ${ }^{1} \cdot$ Marina Trombetti $^{4} \cdot$ Mariarita Perri $^{5} \cdot$ Manuela Colosimo $^{6}$. \\ Gerardo D'Amato $^{7,8} \cdot$ Luca Gallelli $^{9} \cdot$ Roberto Cannataro ${ }^{5,10}$. Clelia Molinario ${ }^{2} \cdot$ Alessia Fazio $^{5}$. \\ Maria Cristina Caroleo ${ }^{5} \cdot$ Erika Cione $^{5}$ (I)
}

Received: 23 March 2020 / Accepted: 21 July 2020 / Published online: 28 July 2020

(c) The Author(s) 2020

\begin{abstract}
The important physiological and pathophysiological roles of intestinal human microbiome (HMB) in human health have been emerging, owing to the access to molecular biology techniques. Herein we evaluated, for the first time, the intestinal HMB through direct hybridization approach using n-counter flex DX technology which bypasses the amplification procedure currently applied by other technologies to study the human microbiome. To this purpose, a clinical study was carried out on fecal samples, recruiting both healthy volunteers (N-FOB) and subjects positive for occult blood (P-FOB). A relevant custom panel of $7916 \mathrm{~S}$ rRNA target gene was engineered and 32 of them displayed a variation between the two clusters of subjects. Our findings revealed that bacteria belonging to Proteobacteria have higher distribution in P-FOB describing dysbiosis. Similarly, Bacteroidetes and Firmicutes phylum display high distribution in P-FOB. Of interest, the presence of Clostridium difficile that belongs to Firmicutes phylum displayed about 70\% of low presence in N-FOB compared to P-FOB subjects. Only one bacterium belonging to the Actinobacteria phylum, the Bifidobacterium bifidum, was present.
\end{abstract}

Keywords Direct detection $\cdot$ Microbiome $\cdot$ Proteobacteria $\cdot$ Clostridium difficile $\cdot$ Eubiosis $\cdot$ Dysbiosis

Concetta Cafiero and Agnese Re have contributed equally to this work.

Electronic supplementary material The online version of this article (https://doi.org/10.1007/s13205-020-02351-w) contains supplementary material, which is available to authorized users.

Erika Cione

erika.cione@unical.it

1 Oncology Unit, SG Moscati Hospital of Taranto, Taranto, Italy

2 Laboratory of Medical Genetics, Alessandria Artemisia, Rome, Italy

3 CNR-Institute of Cell Biology and Neurobiology, Rome, Italy

4 Dietetics and Aesthetic Medicine Section, Alessandria Artemisia, Rome, Italy

5 Department of Pharmacy, Health and Nutritional Sciences-Department of Excellence 2018-2022, University of Calabria, 87036 Rende, CS, Italy

\section{Introduction}

Around $10^{\wedge 12}$ (trillion) complex microbial communities composed of fungi, yeasts, viruses and bacteria reside in the digestive tract, which constitute the human microbiome (HMB) (Marchesi et al. 2016). Its metabolism as well as its genetic set interacts with the host organism defining a close symbiotic relationship (Fischbach and Segre 2016).

6 Department of Microbiology and Virology, Pugliese Ciaccio Hospital, Catanzaro, Italy

7 Department of Endocrine and Metabolic Surgery, Policlinico Universitario A Gemelli-Università Cattolica del Sacro Cuore, Rome, Italy

8 Department of Endocrine and Metabolic Surgery, Mater Olbia Hospital, Olbia, Italy

9 Clinical Pharmacology and Pharmacovigilance Unit, Department of Health Sciences, Mater Domini Hospital, University of Catanzaro, Catanzaro, Italy

10 Nutrics, Nutritional Center, Luzzi, CS, Italy 
As a result, the bacterial composition mirrors the sophisticated commensality interplay that is established with the host organism and within the microbial community (Thursby and Juge 2017; Khangwal and Shukla 2019). Intestinal HMB changes with aging and metabolic disorder, and may contribute to the decline of nutrients' absorption (Dahiya et al. 2017; Kastl et al. 2020). It has been shown that by proper nutritional intervention, HMB can be restored and balanced sustaining eubiosis (Nagpal et al. 2018; Salazar et al. 2017; $\mathrm{Wu}$ and $\mathrm{Wu}$ 2012). Eubiosis is also re-established by antiviral therapy in persistent hepatitis B virus (HBV) infection mouse model ( $\mathrm{Li}$ et al. 2020). HMB is capable of guaranteeing the well-being of the entire organism and its role is essential for the immune system of the host organism ( Wu and Wu 2012; Mu et al. 2016). Environmental factors, poor lifestyles, psycho-physical stress, overnutrition, and pharmacological treatments are able to modify HMB, defining the dysbiosis (Karl et al. 2018). This latter condition is often linked to the lack of intestinal homeostasis which in turn correlates to a wide range of inflammatory conditions (Wen and Duffy 2017). Current knowledge concerning intestinal HMB, using test based on 16S rRNA gene target, points out to the existence of a community of almost 1000 bacterial species classified into five phyla: Actinobacteria, Bacteroidetes, Firmicutes, Proteobacteria and Verrucomicrobia (Rajilic-Stojanovic M and de Vos WM, 2014). The results achieved thus far via high-throughput sequencing (HTS) platforms are very interesting, but the workflow, which includes the library preparation protocols and the enzymatic amplification of the nucleic acid, could lead to different results among the HTS platform used (Salipante et al. 2016; D'Amore et al. 2016; Loman et al. 2012; Lam 2011; Quail et al. 2012; Clooney et al. 2016; Mohammadi et al. 2019). Besides that, sample collection and bacterial DNA extraction as well as the 16S rRNA gene target region represent other important points in the assessment of intestinal HMB (Pollock et al. 2018; Rintala et al. 2017). Therefore, concerns about using HMB analysis is still debated, limiting it to routinely clinical practice (Pollock et al. 2018). In this framework, the assessment of the intestinal HMB in the medical setting may be helpful to dissect symptoms such as episodic colitis attack, diarrhea, constipation, flatulence, and intestinal discomfort (Chichlowski and Rudolph 2015; Simrén et al. 2013). Moreover, intestinal HMB analysis can be fundamental to develop therapeutic and personalized nutritional interventions (Seo et al. 2013). In this work, we attempted to overcome these concerns. To minimize experimental variation, fecal samples were collected and stored with OMNI gene GUT, which proved as a reliable and convenient system to study intestinal HMB (Panek et al. 2018). We performed bacterial DNA extraction with automatic system MagCore HF16 Plus with some modification to improve DNA yield; to avoid library preparation, we performed direct hybridization with n-counter flex DX. To evaluate dysbiosis, fecal occult blood (FOB) samples were collected from patients enrolled via a clinical trial. Of note, several inflammatory intestinal disorders are related to FOB which is not strictly related to colon cancer (Walker 1990; Libby et al. 2018). In this scenario, we have designed in July 2017 the first custom panel "CDR_CNV_Bc_miCrobioTA22586" with 79 bacteria 16S rRNA target genes representative of gut health and impaired in gut inflammation status (Tarallo et al. 2019). Alicyclobacillus acidophilus, Rhizobium radiobacter and Salinibacter ruber are not present in the human gut and were used as negative control of human microbiota bacteria 16S rRNA gene. ACTB, GAPDH and HDAC3 genes were used for monitoring human DNA contamination.

\section{Materials and methods}

\section{Study design, sample collection and HMB community}

Study design and analytical workflow are shown in Fig. 1. Subjects enrolled were divided into two groups: healthynegative for fecal occult blood (herein indicated as N-FOB; $n=48$ ) and positive for fecal occult blood (herein indicated as P-FOB; $n=48$ ). DNA extraction and/or genomic analysis was carried out for N-FOB $n=35$ and P-FOB $n=35$ samples, due to low amount of starting material.

Clinical data are reported in Table 1. The clinical trial was registered at https://clinicaltrials.gov/ct2/show/NCT03 388424. This study was authorized by the ethical committee of University of Catanzaro (protocol \#287, November 2017) and informed consent was obtained from each patient. All procedures were conducted according to the principles expressed in the Declaration of Helsinki and the Guideline for Good Clinical Practice.

$0.5-1 \mathrm{~g}$ of fresh feces were collected in OMNI geneGUT OMR 200 (DNA Genotek Inc, Ottawa, Canada). The stool samples were then carefully mixed with $2 \mathrm{~mL}$ of stabilization buffer in the provided tube and stored at room temperature.

\section{DNA extraction and quantification}

DNA extraction was performed by automatic system MagCore HF16 Plus. Briefly, $2 \mathrm{~mL}$ of feces samples was first exposed to $2 \mathrm{~h}$ of lysozyme (final concentration $250 \mu \mathrm{g} / \mathrm{ml}$ ) treatment at $37^{\circ} \mathrm{C}$, then digested with Proteinase $\mathrm{K}$ solution $\left(10 \mathrm{mg} / \mathrm{ml}\right.$, in GT buffer) at $65^{\circ} \mathrm{C}$ for $3 \mathrm{~h}$. Samples were centrifuged and the bacterial pellet was used for microbial DNA isolation by MagCore protocol cartridge 401 and carrierRNA or cartridge 202. 

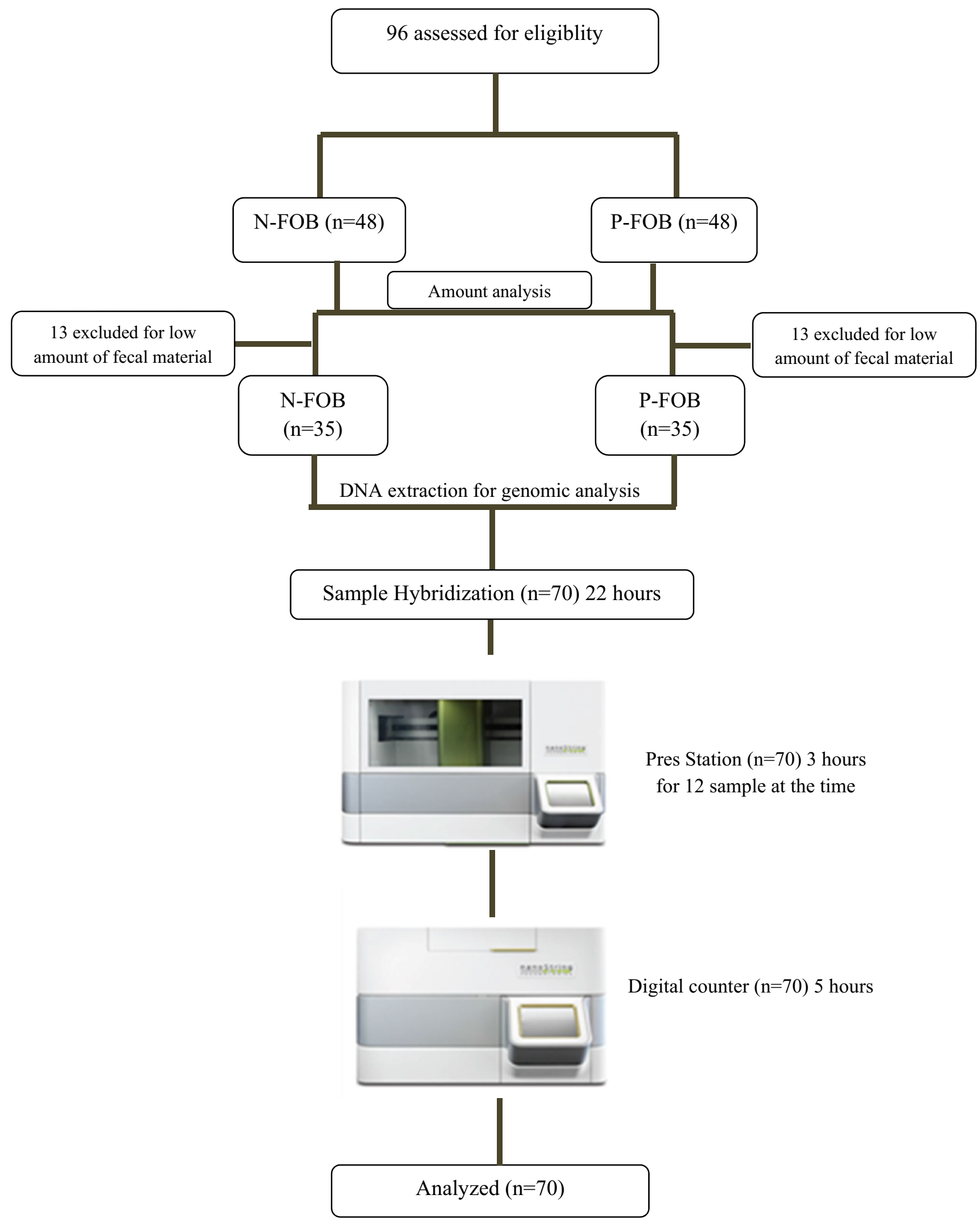

Fig. 1 Study design and analytical workflow. Initially, 48 samples for each group, N-FOB, and P-FOB were collected, 13 samples for each group resulted in a low amount of fecal material. Therefore, DNA extraction for genomic analysis was carried out on 35 samples.
Hybridization was performed for $22 \mathrm{~h}$ and cartridges were posed into the prep station for $3 \mathrm{~h}$ washing and then read to the digital counter for a further $5 \mathrm{~h}$. Then $n$-solver software was used for the analysis
Pres Station ( $\mathrm{n}=70) 3$ hours for 12 sample at the time

Digital counter $(\mathrm{n}=70) 5$ hours 
Table 1 Clinical data of enrolled subjects

\begin{tabular}{|c|c|c|c|c|}
\hline Sample & Age (years) & Male & Female & $\begin{array}{l}\text { Blood amount in stool } \\
\text { sample and its percentage }\end{array}$ \\
\hline N-FOB & Range: $30-70$ & 18 & 30 & $\begin{array}{l}\text { Absence of occult blood } \\
\text { in stool }\end{array}$ \\
\hline P-FOB* & Range: $50-70$ & 23 & 25 & $\begin{array}{l}-100 \text { to } 300 \mathrm{ng} / \mathrm{ml}: 82 \% \\
-300 \text { to } 600 \mathrm{ng} / \mathrm{ml}: 10 \% \\
>800 \mathrm{ng} / \mathrm{ml}: 8 \%\end{array}$ \\
\hline
\end{tabular}

*Data from f-Hb (OC-Sensor Diana-Eiken Chemical-Tokyo)

The DNA quantity and quality measurements were performed on Qubit 3.0 using the Qubit dsDNA HS (High Sensitivity Assay by Thermo Fisher Scientific), based on the fluorescence readouts.

\section{Microbiome panel design, NanoString sample preparation and $\mathrm{nSolver}{ }^{\mathrm{Tm}}$ rcc file acquisition}

Genomic DNA ID from Taxonomy for 16S rRNA gene of 79 bacterial strains was identified, of which three are not present in the human gut and three belong to the host DNA. The panel details are reported in Supplementary Table 1.

For the n-counter flex DX of NanoString Technology, $400 \mathrm{ng}$ of $16 \mathrm{~S}$ rRNA gene was used as input. After $2 \mathrm{~h}$ of AluI digestion at $37^{\circ} \mathrm{C}$, the sample was then hybridized with CodeSet (Supplementary File 1) for $22 \mathrm{~h}$ at $65^{\circ} \mathrm{C}$.

The unhybridized CodeSet was removed with automated purification performed on an nCounter Prep Station, and the remaining target probe complexes were transferred and bound to an imaging surface as previously described (Panek et al. 2018; Geiss et al. 2008). Counts of the two reporter probes were tabulated for each sample by the nCounter Digital Analyzer.

\section{NanoString reproducibility, robustness and Clostridium difficile testing with GeneExpert- Cepheid $^{\mathrm{TM}}$}

The reproducibility of our set of experimental tests was monitored through the negative $(\mathrm{AH} \# 8$ ) and positive (AF \# 6) control probes include in the panel by NanoString, as well as probe value for 12 samples were obtained with two different $\mathrm{n}$-counter flex machine included in the panel and reported in the Supplementary Table 3 as count numbers. The robustness of the technology for the clinical sample was already studied (Veldman-Jones et al. 2015). Finally, to corroborate the proposed experiments, some samples were randomly (1:4) analyzed with a common technology (GeneExpert-Cepheid GXCDIFFBT-CE-10) for Clostridium difficile used in molecular microbiology clinical practice (Supplementary Fig. 1).

\section{Statistical analysis}

Unless indicated, statistical significance was determined by a two-tailed Student's $t$ test with suitable multiple comparison correction. $p$ value of $<0.05$ was regarded as significant. Results are expressed as mean \pm SD. A coefficient of variation (CV) of $60 \%$ was chosen as cutoff into the $n$-solver software analysis. CV is used for comparison between data sets with different units or widely different means. One sample from healthy subjects (N-FOB) was excluded due to the presence of a warning red flag in the $\mathrm{n}$-solver analysis.

\section{Results and discussion}

The complex interaction between organism and microbiome, in both physiological and pathophysiological conditions, has attracted interest from the scientific community either for personalized medicine or to develop probiotics supplement to relieve gut nuisance (Salazar et al. 2017; Wu and $\mathrm{Wu}$ 2012; Mu et al. 2016; Wen and Duffy 2017; Seo et al. 2013; Dahiya et al. 2017; Yadav et al. 2018). Furthermore, intestinal discomfort is characterized by pain and gut inflammation. The panel design was fulfilled for intestinal discomfort and according to the scientific literature (Chichlowski and Rudolph 2015; Simrén et al. 2013).

Currently in the experimental pipeline of 16S rRNA gene sequence with HTS, each procedural step introduces a variation that could influence the final output (Pollock et al. 2018). Therefore, there is an unmet need for standardization of methodology which would enable a reliable and reproducible analysis of valuable human biological samples for studying gut microbiota (Pollock et al. 2018; Rintala et al. 2017; Panek et al. 2018).

Herein, we show that the direct detection of $16 \mathrm{~S}$ rRNA target gene via hybridization method allows us to appreciate the variation of biodiversity (Fig. 2 and Supplementary Table 2) within the collected samples (Table 1). The designed panel based on 16S rRNA gene was suitable for n-counter flex platform considering also the haploid nature of the bacteria DNA (Geiss et al. 2008; Griswold 2018).

The minimum input of nucleic acid used in this study was $400 \mathrm{ng}$. The DNA extraction was performed as described in "Materials and methods". The highest DNA yields (an enrichment of DNA from 40- to 48-fold) were obtained using the cartridge 401 modified protocol compared to cartridge 202 (Table 2).

16S rRNA gene array profiles generate a heat map and hierarchical clustering based on the most differentiated biodiversity as shown in Fig. 2. The analyzed data set is composed of 5.530 count number of 16S rRNA target, related to 79 bacteria recognized by the best hybridization probe and detected in 69 different subjects. 


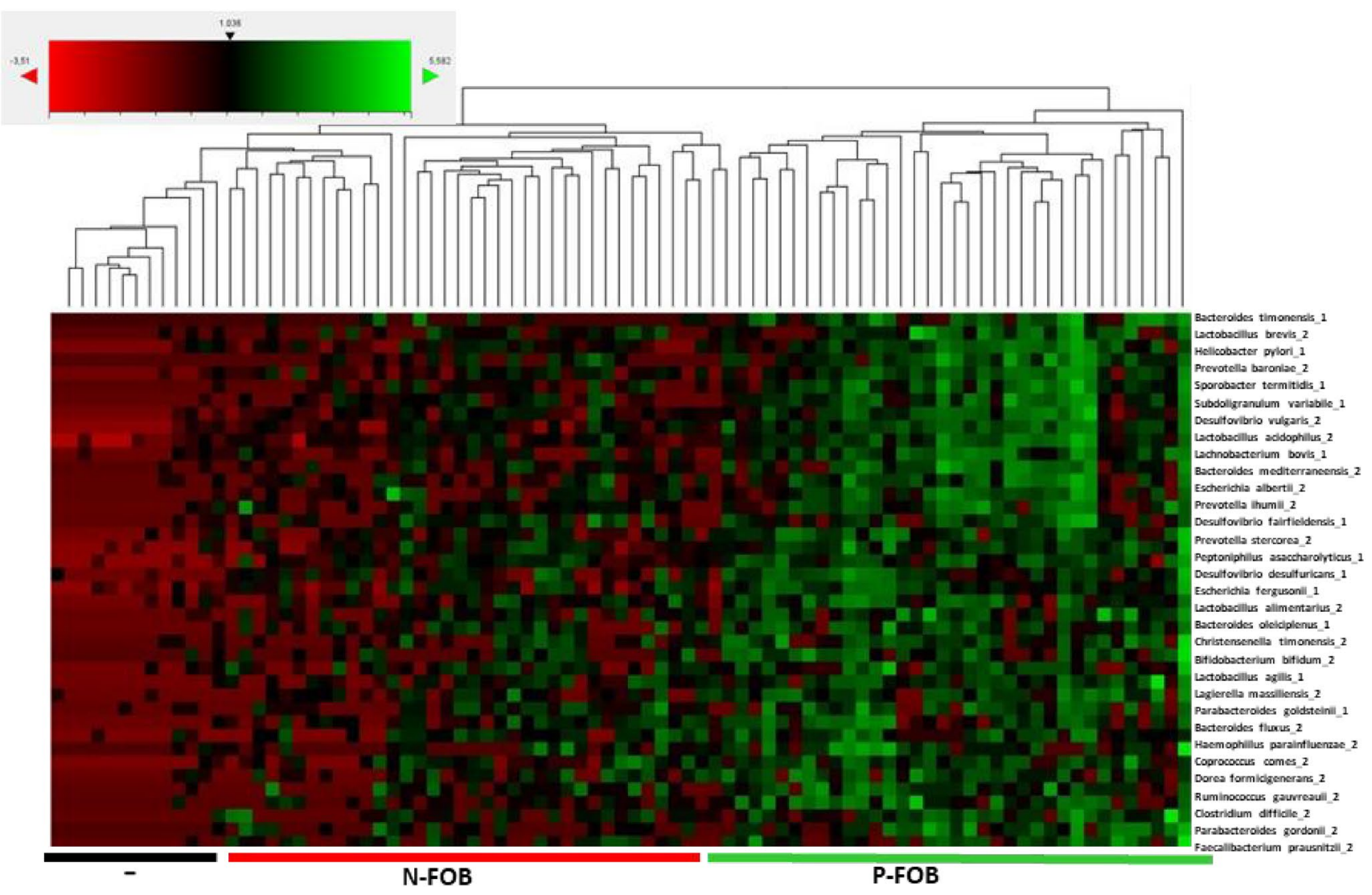

Fig. 2 Heat map and hierarchical clustering of N-FOB $(n=34)$, and P-FOB $(n=35)$ based on the differentially present bacteria 16S rRNA in $\log 2$ ratios. The color intensity represents changes in bacteria variation, ranging from -3.51 to 5.582 . In the analysis, red represents low bacteria abundance and green represents high bacteria abundance. Black represents unchanged bacteria presence as evident by the color reference. $n$-Solver software was used. A coefficient of variation of $60 \%$ was applied
Table 2 Comparison of total DNA extraction from stool samples between $202(\mathrm{G} 1)$ and 401 (G2) cartridge protocols

\begin{tabular}{|c|c|c|c|c|c|}
\hline G1 & $\begin{array}{l}\text { Total DNA ng/ } \mu l \\
\text { \# } 202 \text { cartridge }\end{array}$ & G2 & $\begin{array}{l}\text { Total DNA ng/ } \mu \mathrm{l} \\
\text { \# } 401 \text { cartridge }\end{array}$ & $\begin{array}{l}\text { Enrichment G2 } \\
\text { vs G1 }\end{array}$ & $p$ value \\
\hline 1 & $1.5227 \pm 0.0148$ & 1 & $61.8962 \pm 0.0176 * * *$ & 40.65 & $<0.001$ \\
\hline 2 & $1.3951 \pm 0.0080$ & 2 & $62.4069 \pm 0.0142 * * *$ & 44.73 & $<0.001$ \\
\hline 3 & $1.2539 \pm 0.0093$ & 3 & $60.5769 \pm 0.0167 * * *$ & 48.31 & $<0.001$ \\
\hline 4 & $1.0769 \pm 0.0092$ & 4 & $52.1298 \pm 0.0212 * * *$ & 48.40 & $<0.001$ \\
\hline
\end{tabular}

Data from the heat map, reported in Fig. 2 and in Sup-

The samples were classified according to two clusters: P-FOB (in green) and N-FOB (in red) negative control (in black). Of 79 bacteria, 32 displayed variation between the two clusters. The differential bacteria distribution in P-FOB compared to N-FOB showed an increased presence of part of them in P-FOB subjects. The agglomerative cluster of the heat map with a dendrogram tree showed an obvious clustering of $16 \mathrm{~S}$ rRNA-specific bacteria genes that ranged from -3.51 up to 5.582 in P-FOB subjects, as illustrated in Fig. 2. Red indicates decrease up to -3.51 of $16 \mathrm{~S}$ rRNA-specific bacteria genes, while green indicates an increase up to 5.582 of 16S rRNA-specific bacteria genes. plementary Table 2 , show that bacteria biodiversity between the two groups is greatly different. The information obtained is in agreement with those reported in a recently paper from Tarallo et al. (2019).

In particular, bacteria belonging to Bacteroidetes phylum was recently reviewed for its role in metabolic disease, among which Prevotella assumes an important meaning (Johnson et al. 2017). Likewise, Proteobacteria phylum such as Helicobacter pylori, Desulfovibrio vulgaris, Desulfovibrio fairfieldensis, Desulfovibrio desulfuricans, Escherichia fergusonii, and Haemophiilus parainfluenzae 
are higher in pathophysiological gut status according to our heat map results and previous studies (Tarallo et al. 2019; Rizzatti et al. 2017). Additionally, Libby et al. (2019) pointed out a significant correlation for fecal blood presence and the increasing risk of dying from circulatory, respiratory and digestive diseases (excluding colorectal cancer) as well as neuropsychological, blood and endocrine disease (Walker 1990). Therefore, defining the nature of dysbiosis for the presence of blood in feces could prevent these risks also combining biotechnological intervention (Khangwal and Shukla 2019). The observations described here have two possible implications concerning gut dysbiosis. First, the dysbiosis in the microbiome linked to blood feces presence might also be used to explore the underlying reasons for different patterns of mortality in different populations across the world. Second, the proper prebiotics/probiotics intervention could modify microbiome dysbiosis and possibly blood feces biomarker to reduce the risk of premature mortality.

In addition, Firmicutes phylum abundances were significantly different in cancer stool sample compared to healthy or the adenoma sample (Tarallo et al. 2019). In this context, results from our trial showed a higher presence of Clostridium difficile that displayed about $70 \%$ of low presence in N-FOB compared to P-FOB subjects (21/34 red dots of $\mathrm{N}-\mathrm{FOB}$ ) vs $24 / 35$ green dots in $\mathrm{P}-\mathrm{FOB})$. These data assume particular interest in preventing Clostridium difficile infection, where in extreme condition fecal microbiome transplantation can occur (Juul et al. 2018). The importance of testing microbiome is becoming more evident, especially considering that the gut axis interaction involves several organs (brain, kidney, liver, bone, skin, adipose tissue and heart) (Ahlawat and Sharma 2020). Consequently, comprehensive information of the types of microbes that reside in the human gut is necessary before any kind of pharmacological intervention that attempts to alter the microbiome. Our methods could be applied successfully on long-term archived fecal sample sets, originally collected for testing fecal blood, to stratify patients and could be used for microbiome-based early biomarker discovery for gut health (Rounge et al. 2018). Of note, this is the first time that direct hybridization with n-counter flex DX platform was applied to microbiome studies and although second generation of platform already exists, both produced equivalent signals and signal deviations (Yu et al. 2019). Finally, it is important to underline that using two different $\mathrm{n}$-counter flex machines, we obtained similar results $(p>0.05)$ showing both, reproducibility and robustness of the n-counter technology. Moreover, comparing the results obtained using a microbiological clinical diagnostic tool for Clostridium difficile with the results obtained from n-counter flex DX, the presence of this bacterium in P-FOB subjects was successfully reported, corroborating our results.

\section{Conclusions}

The complex interaction between organism and microbiome, both in the physiology and in the pathophysiology, has aroused much interest in the last years. The microbiome represents one of the most significant new topics in the biomedical field that has concretely entered the medi$\mathrm{cal} /$ therapeutic field. This is the first study undertaken to determine HMB by direct hybridization using $n$-counter flex DX technology. This approach gives a useful tool for robust diagnostic/screening profiles of the microbiome. It is an innovative and exportable diagnostic model in the laboratory medicine practice. Furthermore, as the HMB panel could have strength up to 800 bacteria, this technology could lead to new biomarkers' discovery of microbiome and pave the way for the identification of therapeutic targets for human well-being.

Author contributions $\mathrm{CC}$ and $\mathrm{AR}$ assessed and performed the fecal DNA extraction method. LG and MC managed the clinical trials. CM performed extraction and DNA quantification. MP performed hybridization experiments on n-counter-flex. EC, MCC, CC and AR analyzed the data. All other authors facilitate the study. All authors read the manuscript for the final approved version.

Funding The n-counter flex DX platform was acquired with the fund of Calabria Regional Council POR FSE 2007/2013 \#6 prot 257996 to E.C., R.C., M.C.C. and M.P. Artemisia Lab Srl, and GalaScreen Srl funded the study without being involved in the clinical study design.

Data availability Material and raw data are available.

\section{Compliance with ethical standards}

Conflict of interest C.C., T.M. and E.C. are co-inventors of an Italian patent deposit held by Artemisia Lab Srl, and GalaScreen Srl (Ref. Number: 102018000011030 12/12/2018).

Ethical approval Ethical Committee approval of University of Catanzaro (protocol \#287, November 2017), in accordance with the Declaration of Helsinki and the Guideline for Good Clinical Practice.

Consent to participate Written informed consent was given by each participant.

Consent for publication Each participant agrees to publish data.

Code availability nSolver Analysis Software is an integrated analysis platform for nCounter data and it is free available.

Open Access This article is licensed under a Creative Commons Attribution 4.0 International License, which permits use, sharing, adaptation, distribution and reproduction in any medium or format, as long as you give appropriate credit to the original author(s) and the source, provide a link to the Creative Commons licence, and indicate if changes were made. The images or other third party material in this article are included in the article's Creative Commons licence, unless indicated otherwise in a credit line to the material. If material is not included in the article's Creative Commons licence and your intended use is not 
permitted by statutory regulation or exceeds the permitted use, you will need to obtain permission directly from the copyright holder. To view a copy of this licence, visit http://creativecommons.org/licenses/by/4.0/.

\section{References}

Ahlawat S, Sharma KK (2020) Gut-organ axis: a microbial outreach and networking. Lett Appl Microbiol. https://doi.org/10.1111/ lam.13333 (Accepted Author Manuscript)

Chichlowski M, Rudolph C (2015) Visceral pain and gastrointestinal microbiome. J Neurogastroenterol Motil 21(2):172-181. https:// doi.org/10.5056/jnm15025

Clooney AG, Fouhy F, Sleator RD, O'Driscoll A, Stanton C, Cotter PD, Claesson MJ (2016) Comparing apples and oranges?: next generation sequencing and its impact on microbiome analysis. PLoS One 11(2):e0148028. https://doi.org/10.1371/journ al.pone.0148028. (eCollection 2016)

Dahiya DK, Renuka PM, Shandilya UK, Dhewa T, Kumar N, Kumar S, Puniya AK, Shukla P (2017) Gut microbiota modulation and its relationship with obesity using prebiotic fibers and probiotics: a review. Front Microbiol 8(563):2017. https://doi. org/10.3389/fmicb.2017.00563 (eCollection 2017)

D’Amore R, Ijaz UZ, Schirmer M, Kenny JG, Gregory R, Darby AC, Shakya M, Podar M, Quince C, Hall N (2016) A comprehensive benchmarking study of protocols and sequencing platforms for 16s rRNA community profiling. BMC Genomics 17:55. https ://doi.org/10.1186/s12864-015-2194-9

Fischbach MA, Segre JA (2016) Signaling in host-associated microbial communities. Cell 164(6):1288-1300. https://doi. org/10.1016/j.cell.2016.02.037

Geiss GK, Bumgarner RE, Birditt B, Dahl T, Dowidar N, Dunaway DL, Fell HP, Ferree S, George RD, Grogan T et al (2008) Direct multiplexed measurement of gene expression with colorcoded probe pairs. Nat Biotechnol 26(3):317-325. https://doi. org/10.1038/nbt 1385

Griswold A (2018) Genome packaging in prokaryotes: the circular chromosome of E. Coli. Nat Educ 1(1):57

Johnson EL, Heaver SL, Walters WA, Ley RE (2017) Microbiome and metabolic disease: revisiting the bacterial phylum Bacteroidetes. J Mol Med (Berl) 95(1):1-8. https://doi.org/10.1007/ s00109-016-1492-2

Juul FE, Garborg K, Bretthauer M, Skudal H, Øines MN, Wiig H, Rose $\varnothing$, Seip B, Lamont JT, Midtvedt T, Valeur J, Kalager $M$ et al (2018) Fecal microbiota transplantation for primary Clostridium difficile infection. N Engl J Med 378(26):25352536. https://doi.org/10.1056/NEJMc1803103

Karl JP, Hatch AM, Arcidiacono SM, Pearce SC, Pantoja-Feliciano IG, Doherty LA, Soares JW (2018) Effects of psychological, environmental and physical stressors on the gut microbiota. Front Microbiol 9:2013. https://doi.org/10.3389/fmicb .2018 .02013

Kastl AJ Jr, Terry NA, Wu GD, Albenberg LG (2020) The structure and function of the human small intestinal microbiota: current understanding and future directions. Cell Mol Gastroenterol Hepatol 9(1):33-45. https://doi.org/10.1016/j.jcmgh.2019.07.006

Khangwal I, Shukla P (2019) Combinatory biotechnological intervention for gut microbiota. Appl Microbiol Biotechnol 103(9):36153625. https://doi.org/10.1007/s00253-019-09727-w

Lam HY, Clark MJ, Chen R, Chen R, Natsoulis G, O'Huallachain M, Dewey FE, Habegger L, Ashley EA, Gerstein MB, Butte AJ, Ji HP, Snyder M (2011) Performance comparison of whole-genome sequencing platforms. Nat Biotechnol 30(1):78-82. https://doi. org/10.1038/nbt.2065
Li X, Wu S, Du Y, Yang L, Li Y, Hong B (2020) Entecavir therapy reverses gut microbiota dysbiosis induced by hepatitis $\mathrm{B}$ virus infection in a mouse model. Int J Antimicrob Agents. https://doi. org/10.1016/j.ijantimicag.2020.106000

Libby G, Fraser CG, Carey FA, Brewster DH, Steele RJC (2018) Occult blood in faeces is associated with all-cause and non-colorectal cancer mortality. Gut 67(12):2116-2123. https://doi.org/10.1136/ gutjnl-2018-316483

Loman NJ, Misra RV, Dallman TJ, Constantinidou C, Gharbia SE, Wain J, Pallen MJ (2012) Performance comparison of benchtop high-throughput sequencing platforms. Nat Biotechnol 30(5):434 439. https://doi.org/10.1038/nbt.2198

Marchesi JR, Adams DH, Fava F, Hermes GD, Hirschfield GM, Hold G, Quraishi MN, Kinross J, Smidt H, Tuohy KM, Thomas LV, Zoetendal EG, Hart A (2016) The gut microbiota and host health: a new clinical frontier. Gut 65(2):330-339. https://doi. org/10.1136/gutjnl-2015-309990

Mohammadi A, Kelly OB, Smith MI, Kabakchiev B, Silverberg MS (2019) Differential miRNA expression in ileal and colonic tissues reveals an altered immunoregulatory molecular profile in individuals with Crohn's disease versus healthy subjects. J Crohns Colitis 13(11):1459-1469. https://doi.org/10.1093/ecco-jcc/jjz076

Mu C, Yang Y, Zhu W (2016) Gut microbiota: the brain peacekeeper. Front Microbiol 7:345. https://doi.org/10.3389/fmicb.2016.00345

Nagpal R, Mainali R, Ahmadi S, Wang S, Singh R, Kavanagh K, Kitzman DW, Kushugulova A, Marotta F, Yadav H (2018) Gut microbiome and aging: physiological and mechanistic insights. Nutr Healthy Aging 4(4):267-285. https://doi.org/10.3233/NHA170030

Panek M, Čipčić Paljetak H, Barešić A, Perić M, Matijašić M, Lojkić I, Vranešić Bender D, Krznarić Ž, Verbanac D (2018) Methodology challenges in studying human gut microbiota - effects of collection, storage, DNA extraction and next generation sequencing technologies. Sci Rep 8(1):5143. https://doi.org/10.1038/s4159 8-018-23296-4

Pollock J, Glendinning L, Wisedchanwet T, Watson M (2018) The madness of microbiome: attempting to find consensus "best practice" for $16 \mathrm{~S}$ microbiome studies. Appl Environ Microbiol 84(7):e02627-e2717. https://doi.org/10.1128/AEM.02627-17

Quail MA, Smith M, Coupland P, Otto TD, Harris SR, Connor TR, Bertoni A, Swerdlow HP, Gu Y (2012) A tale of three next generation sequencing platforms: comparison of Ion Torrent, Pacific Biosciences and Illumina MiSeq sequencers. BMC Genom 13:341. https://doi.org/10.1186/1471-2164-13-341

Rajilić-Stojanović M, de Vos WM (2014) The first 1000 cultured species of the human gastrointestinal microbiota. FEMS Microbiol Rev 38(5):996-1047. https://doi.org/10.1111/1574-6976.12075

Rintala A, Pietilä S, Munukka E, Eerola E, Pursiheimo JP, Laiho A, Pekkala S, Huovinen P (2017) Gut microbiota analysis results are highly dependent on the 16S rRNA gene target region, whereas the impact of DNA extraction is minor. J Biomol Tech 28(1):1930. https://doi.org/10.7171/jbt.17-2801-003

Rizzatti G, Lopetuso LR, Gibiino G, Binda C, Gasbarrini A (2017) Proteobacteria: a common factor in human diseases. Biomed Res Int. https://doi.org/10.1155/2017/9351507

Rounge TB, Meisal R, Nordby JI, Ambur OH, de Lange T, Hoff G (2018) Evaluating gut microbiota profiles from archived fecal samples. BMC Gastroenterol 18(1):171. https://doi.org/10.1186/ s12876-018-0896-6

Salazar N, Valdés-Varela L, González S, Gueimonde M, de Los ReyesGavilán CG (2017) Nutrition and the gut microbiome in the elderly. Gut Microbes 8(2):82-97. https://doi.org/10.1080/19490 976.2016.1256525

Salipante SJ, Kawashima T, Rosenthal C, Hoogestraat DR, Cummings LA, Sengupta DJ, Harkins TT, Cookson BT, Hoffman NG (2016) Erratum for Salipante et al., Performance comparison of

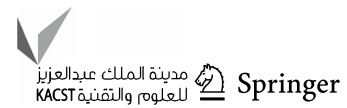


illumina and ion torrent next-generation sequencing platforms for 16S rRNA-based bacterial community profiling. Appl Environ Microbiol. 82(14):4453. https://doi.org/10.1128/AEM.01390-16

Seo AY, Kim N, Oh DH (2013) Abdominal bloating: pathophysiology and treatment. J Neurogastroenterol Motil 19(4):433-453. https ://doi.org/10.5056/jnm.2013.19.4.43320

Simrén M, Barbara G, Flint HJ, Spiegel BM, Spiller RC, Vanner S, Verdu EF, Whorwell PJ, Zoetendal EG, Committee RF (2013) Intestinal microbiota in functional bowel disorders: a Rome foundation report. Gut 62(1):159-176. https://doi.org/10.1136/gutjn 1-2012-302167

Tarallo S, Ferrero G, Gallo G, Francavilla A, Clerico G, Realis Luc A, Manghi P, Thomas AM, Vineis P, Segata N, Pardini B, Naccarati A, Cordero F (2019) Altered fecal small RNA profiles in colorectal cancer reflect gut microbiome composition in stool samples. mSystems. 4(5):e00289-e00319. https://doi.org/10.1128/mSyst ems.00289-19 (Erratum in: mSystems. 2020 Feb 18;5(1))

Thursby E, Juge N (2017) Introduction to the human gut microbiota. Biochem J 474(11):1823-1836. https://doi.org/10.1042/BCJ20 160510.22

Veldman-Jones MH, Brant R, Rooney C et al (2015) Evaluating robustness and sensitivity of the nanostring technologies
nCounter platform to enable multiplexed gene expression analysis of clinical samples. Cancer Res 75(13):2587-2593. https://doi. org/10.1158/0008-5472.CAN-15-0262

Walker HK (1990) The origins of the history and physical examination. In: Walker HK, Hall WD, Hurst JW (eds) Clinical methods: the history, physical, and laboratory examinations, 3rd edn. Butterworths, Boston (Chapter 1)

Wen L, Duffy A (1475S) Factors influencing the gut microbiota, inflammation, and type 2 diabetes. J Nutr 147(7):1468S-1475S. https://doi.org/10.3945/jn.116.240754

Wu HJ, Wu E (2012) The role of gut microbiota in immune homeostasis and autoimmunity. Gut Microbes 3(1):4-14. https://doi. org/10.4161/gmic. 19320

Yadav R, Kumar V, Baweja M, Shukla P (2018) Gene editing and genetic engineering approaches for advanced probiotics: a review. Crit Rev Food Sci Nutr 58(10):1735-1746. https://doi. org/10.1080/10408398.2016.1274877

Yu L, Bhayana S, Jacob NK, Fadda P (2019) Comparative studies of two generations of NanoString nCounter system. PLoS One 14(11):e0225505. https://doi.org/10.1371/journal.pone.0225505 